\title{
Metodologia d'avaluació de pràctiques externes curriculars
}

\author{
Mari Carmen Dorado Dols \\ dorado@uji.es \\ María Isabel Beas Collado \\ mbeas@uji.es \\ Raül Burriel Calvet \\ raul.burriel@uji.es \\ Laura García Pla \\ Igarcia@uji.es
}

\section{Resum}

Introducció: L'OIPEP és l'encarregada de la gestió de les pràctiques externes curriculars dels graus i màsters universitaris de la Universitat Jaume I (UJI), així com de la seua avaluació institucional. Aquesta avaluació, fonamental per a garantir la qualitat de les pràctiques, es troba vinculada amb el pla estratègic de la universitat. Per això resulta imprescindible aconseguir una mostra representativa de la població d'interés: estudiantat, supervisors/es i tutors/es.

Objectiu: Augmentar la taxa de resposta a les enquestes d'avaluació de pràctiques dels col-lectius implicats, mitjançant un canvi en la metodologia de recollida de dades.

Mètode: La recollida de dades comença en el moment que finalitzen les primeres pràctiques del curs (al voltant de novembre) i finalitza quan han acabat les últimes pràctiques del curs (octubre de l'any següent). Participen l'estudiantat que ha realitzat pràctiques externes curriculars, els supervisors/es de les entitats d'acollida i el professorat tutor. Les enquestes es realitzen en línia, mitjançant LimeSurvey. La nova metodologia de recollida de dades afecta només l'estudiantat $\mathrm{i}$ els supervisors (no així els tutors/es de la universitat, ja que aquests emplenen una única enquesta per titulació tutoritzada al final del curs) i ha consistit en: 1) l'automatització de l'enviament de les enquestes de manera contingent a la finalització de les pràctiques (15 dies després); 2) l'enviament de missatges personalitzats sol-licitant completar l'enquesta; 3) l'enviament de recordatoris personalitzats només en cas que encara no s'haja contestat l'enquesta (dos recordatoris, freqüència quinzenal). Les dades recollides s'han analitzat mitjançant el programa estadístic SPSS. 
Resultats: La resposta s'ha incrementat un $44,77 \%$ per a l'estudiantat i un $45,42 \%$ per als supervisors, respecte el curs 2015-2016. Per als tutors i tutores no s'ha vist cap canvi.

Conclusions: El canvi en la metodologia ha suposat un notable increment en la mostra d'estudiantat i supervisors/es. La no contingència en l'enviament de l'enquesta a tutors i tutores podria ser un dels motius de la falta de canvi en la seua taxa de resposta a l'enquesta.

Paraules clau: metodologia, pràctiques externes, avaluació.

\begin{abstract}
Introduction: The OIPEP manages the external curricular internships of the university's degrees and masters at Universitat Jaume I (UJI). It also manages its institutional evaluation. This evaluation is fundamental to guarantee the quality of the internships and it is linked to the strategic plan of the university. This is why it is essential to obtain a representative sample of the sample of interest: students, supervisors and tutors.

Objective: Increase the response rate of the work placements evaluation surveys. Targeting the groups involved by changing the methodology of data collection.

Method: Data collection begins with the first course placements (November) and ends when the internships have finished (October). The sample is formed by the students that have carried out curricular external internships, the supervisors of the co-operating entities and the tutors of the intern students. The surveys are filed-in online, using the LimeSurvey. The new methodology to collect data consisted in: 1) Sending of surveys automatically contingent to the completion of the work placements (15 days later) (except for the tutor, who fills-in a single survey for the tutored degree at the end of the course); 2) Sending of personalized messages requesting to complete the survey; 3 ) Sending personalized reminders (two reminders on a fortnight frequency). The data collected were analysed using the SPSS statistical program.

Results: The answer rate has increased in $44.77 \%$ for students and $45.42 \%$ for supervisors, compared to 2015-2016. Tutor-wise, there has been no change.

Conclusions: The methodological change has meant a significant increase in the sample of students and supervisors. The non-contingency in sending the survey to tutors could be one of the reasons for the lack of change in its rate of response to the survey.
\end{abstract}

Keywords: methodology, placements, internships, evaluation.

\title{
Introducció
}

L'Oficina d'Inserció Professional i Estades en Pràctiques (OIPEP) té l'objectiu de millorar l'ocupabilitat i facilitar la inserció professional de l'estudiantat i titulats i titulades UJI mitjançant la incorporació de valor afegit a la seua formació i preparant-los per a treballar en l'àmbit de les seues respectives professions, incloent-hi l'entorn internacional, així com amb la cooperació amb institucions i empreses. Per a assolir aquest objectiu es duen a terme una sèrie de programes i s'ofereixen un conjunt de serveis com pràctiques externes curriculars en les titulacions oficials, pràctiques internacionals, orientació cap a l'ocupació i la inserció professional, formació cap a 
l'ocupació, fires i jornades, presentacions corporatives (OCUPARTY), agència de col·locació, sensibilització corporativa i observatori ocupacional.

En el moment actual, I'OIPEP depèn del Vicerectorat d'Estudiantat i Compromís Social i compta amb un consell assessor d'inserció professional.

A més, l'OIPEP és l'encarregada de la gestió de les pràctiques externes curriculars dels graus i màsters universitaris de la Universitat Jaume I (UJI), així com de la seua avaluació institucional. Aquesta avaluació, fonamental per a garantir la qualitat de les pràctiques, es troba vinculada amb el pla estratègic de la universitat. També, aquesta avaluació permet fer un seguiment de les pràctiques per titulacions per tal d'efectuar una millora continuada, modificar els plans d'estudi si cal i, en definitiva, rendir comptes a la societat. És per això que resulta imprescindible disposar de dades de qualitat i, per tant, necessitem aconseguir una mostra representativa de la població d'interés: estudiantat, supervisors/es i tutors/es.

Segons Díaz de Rada (2012), la utilització d'Internet aporta, a partir dels avantatges i inconvenients de les enquestes postals autoadministrades, avantatges com:

- Major rapidesa en la recollida d'informació.

- Millora en el disseny del qüestionari per la possibilitat d'ús d'elements multimèdia.

- Menor cost.

Però el que fa viable la utilització d'enquestes per Internet és la representativitat de la mostra respecte de la població que es vol estudiar, a més de l'eficàcia de la pròpia enquesta electrònica com a mètode davant d'altres tipus d'estudis (Páramo 2007). A més, autors com Dillman et al. (2009) proposen mètodes combinats (mixed-mode surveys) després d'haver comprovat l'eficàcia de realitzar una enquesta telefònica entre les persones que no havien contestat una enquesta per internet, al passar d'una taxa de resposta del $12,7 \%$ a una del $44,9 \%$ per telèfon.

L'objectiu d'aquest treball és donar a conéixer les millores aplicades al procediment d'avaluació de pràctiques per a augmentar la taxa de resposta de les enquestes, i així millorar la representativitat de les dades. Per a aconseguir-lo, hem realitzat un canvi en la metodologia d'avaluació, que combina qüestionari en línia i reforç telefònic, que us presentem a continuació.

\section{Mètode}

Mostra

La nova metodologia ha sigut aplicada únicament a dos col-lectius: l'estudiantat que ha realitzat pràctiques en el curs 2015-2016 i els supervisors i supervisores de les entitats d'acollida. Pot veure's amb més detall la configuració de la mostra en la taula 1. 
Taula 1

Població de l'estudi

\begin{tabular}{lll}
\hline Estudiantat & $\mathrm{N}=1839$ & $\begin{array}{l}\text { Grau:1522 } \\
\text { Màster: } 317\end{array}$ \\
\hline Supervisors/es & $\mathrm{N}=1583$ & Grau:1287 \\
& & Màster:296 \\
\hline
\end{tabular}

\section{Instruments}

Les dades necessàries per a dur a terme aquesta avaluació institucional han sigut recollides mitjançant un procediment d'enquesta. Aquesta és diferent segons el collectiu; per tant, es disposa de dues enquestes, una per a l'alumnat i una altra per al personal supervisor de les entitats.

Pel que fa a l'enquesta de l'estudiantat, aquesta recull informació sobre distintes variables. En primer lloc, es pregunta sobre el nivell d'estudis i titulació cursada durant la realització de les pràctiques. Seguidament, es demana informació sobre les característiques de les pràctiques: dedicació setmanal, durada de les pràctiques, ajuda econòmica i inserció laboral en l'entitat. Es comenten també aspectes de les pràctiques com l'organització, el projecte formatiu, l'aportació personal i l'aprenentatge de les pràctiques (mitjançant una escala Likert d'1, "Totalment insatisfet/a», a 5, «Totalment satisfet/a»). A més a més, s'avaluen aspectes pel que fa a l'entitat com la flexibilitat horària, els materials posats a disposició de l'alumnat, la valoració del treball realitzat per part de l'entitat, l'ambient de treball i l'adaptació als interessos professionals (mitjançant una escala Likert d'1, "Totalment en desacord», a 5, "Totalment d'acord»). També es fa una valoració del supervisor/a i del tutor/a pel que fa al procés d'acompanyament i supervisió que han executat (mitjançant una escala Likert d'1, «Totalment insatisfet/a», a 5, "Totalment satisfet/a»). Finalment, s'avalua el nivell de competències percebudes després de l'estada i la satisfacció global amb les pràctiques realitzades (mitjançant una escala Likert d'1, «Molt baix", a 5, «Molt alt»).

Pel que fa l'enquesta de supervisors/es, recull en primer lloc el nivell d'estudis i la titulació de l'estudiant acollit. A continuació, es pregunta sobre la inserció laboral de l'estudiant en l'entitat $\mathrm{i}$ sobre el nivell de competències d'aquest/a (mitjançant una escala Likert d'1, «Molt baix», a 5, «Molt alt»). També es valora el projecte formatiu desenvolupat, l'organització, la coordinació amb el tutor/a de la universitat i el grau de satisfacció amb aquest/a (mitjançant una escala Likert d'1, "Totalment insatisfet/a», a 5, «Totalment satisfet/a»). S'incideix en la valoració que el supervisor/a fa sobre què li han aportat les pràctiques a l'estudiant/a, així com de quina manera han revertit i quina aportació han fet les pràctiques a l'entitat d'acollida (mitjançant una escala Likert d'1, «Totalment en desacord», a 5, «Totalment d'acord»). Finalment, s'avalua la satisfacció global amb les pràctiques realitzades per l'estudiant/a i es pregunta si tenen intenció de tornar a acollir estudiantat el pròxim curs (mitjançant una escala Likert d'1, «Totalment insatisfet/a», a 5, «Totalment satisfet/a»).

\section{Procediment}

El procés de recollida de dades es va iniciar al novembre de 2016 amb la finalització de les primeres pràctiques del curs i va acabar al mes d'octubre de 2017 , quan es van donar per finalitzades les últimes estades. 
Les enquestes s'han realitzat en línia, mitjançant dues eines informàtiques combinades: el programa de codi obert LimeSurvey y una aplicació d'enquestes d'estades en pràctiques (EEP) desenvolupada per la Unitat d'Anàlisi i Desenvolupament TI de la Universitat Jaume I. El programa LimeSurvey s'utilitza per a dissenyar els qüestionaris, generar URL úniques i individualitzades per a cada persona que s'ha d'enquestar, gestionar les respostes $\mathrm{i}$, finalment, descarregar-les. Per una altra banda, i en paral-lel, l'EEP permet gestionar la població que s'ha d'enquestar i també l'enviament de correus electrònics personalitzats a la població (que inclouen les URL generades amb LimeSurvey). Permet també gestionar els recordatoris. La característica més destacable de l'EEP és que permet enviar els correus de manera automàtica a estudiantat i persones supervisores 15 dies després de la finalització de l'estada en pràctiques, de manera que no cal estar pendent d'aquesta situació, només cal anar carregant població i enviar correus de manera periòdica. El procés de treball es descriu esquemàticament a la taula 2.

Taula 2

Procés de treball amb LimeSurvey i EEP per a l'enviament de les enquestes d'avaluació de pràctiques

\begin{tabular}{|l|l|l|}
\hline Pas & Programa & Acció \\
\hline 1 & LimeSurvey & Elaboració dels qüestionaris \\
\hline 2 & EEP & $\begin{array}{l}\text { Elaboració del text dels missatges de correu electrònic que } \\
\text { s'enviaran a la població }\end{array}$ \\
\hline 3 & EEP & Gestió de la població que s'ha enquestar \\
\hline 4 & LimeSurvey & Generació de les URL úniques i individualitzades \\
\hline 5 & EEP & Enviament de correus i recordatoris \\
\hline 6 & LimeSurvey & $\begin{array}{l}\text { Emmagatzemament de les respostes per a la seua posterior } \\
\text { exportació }\end{array}$ \\
\hline
\end{tabular}

Per a augmentar la taxa de resposta en les enquestes, tal i com ha estat establert en l'objectiu, la nova metodologia de recollida de dades presenta les següents característiques: en primer lloc, s'ha automatitzat l'enviament de les enquestes de manera contingent a la finalització de les pràctiques (15 dies després). En segon lloc, s'envien missatges personalitzats sol-licitant completar l'enquesta. Finalment, l'enviament de recordatoris és també personalitzat (2 recordatoris, freqüència quinzenal). En la taula 3 pot veure's una comparativa de la metodologia d'abans respecte a la nova metodologia utilitzada. 
Taula 3

Metodologia de recollida de dades

\begin{tabular}{|c|c|}
\hline Metodologia d'abans & Nova metodologia \\
\hline $\begin{array}{l}\text { - Enviament únic al final del curs } \\
\text { - Enviament manualges genèrics } \\
\text { - Enviament de recordatoris } \\
\text { indiscriminat }\end{array}$ & $\begin{array}{l}\text { - Enviament coaió de cada pràctica } \\
\text { - Essatges personalitzats } \\
\text { - Enviament de recordatoris } \\
\text { personalitzats }\end{array}$ \\
\hline
\end{tabular}

Anàlisi

Les dades recollides s'han analitzat mitjançant el programa estadístic SPSS. S'han realitzat proves khi quadrat (X2) per comprovar si la diferència de distribució de respostes en cada collectiu (estudiantat i tutors) entre 2016 i 2017 són estadísticament significatives.

\section{Resultats}

Una volta finalitzat el període de recollida de dades i la seua posterior anàlisi, els resultats obtinguts poden trobar-se en les taules següents: figura 1, figura 2 i taula 4.

En la figura 1 es mostra la taxa de resposta obtinguda en el curs passat (2015-2016) amb l'antiga metodologia i la taxa de resposta del curs actual (2016-2017) amb l'aplicació de la nova metodologia. Tot i que aquesta nova metodologia ha estat aplicada només al col-lectiu estudiantat i supervisor/es, en la taula de resultats s'ha in clòs també la taxa de resposta dels tutors i tutores.

En la figura 2 pot observar-se l'increment, expressat en percentatge, de la taxa de resposta d'aquest curs respecte al curs anterior. D'aquesta forma, pot veure's amb claredat quin ha estat l'augment en la resposta amb l'aplicació de la nova metodologia i si s'han produït canvis respecte a l'any anterior en tutors/es.

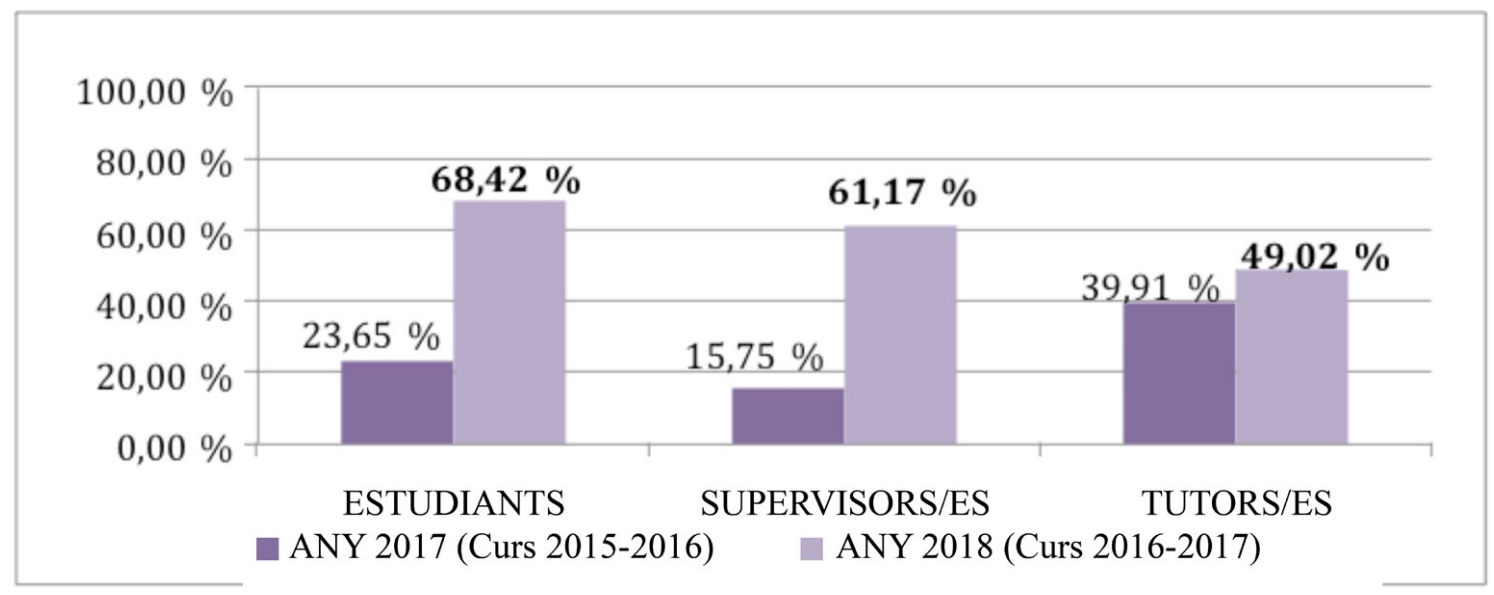

Figura 1

Comparativa taxa de resposta curs 2015-2016 - curs 2016-2017 


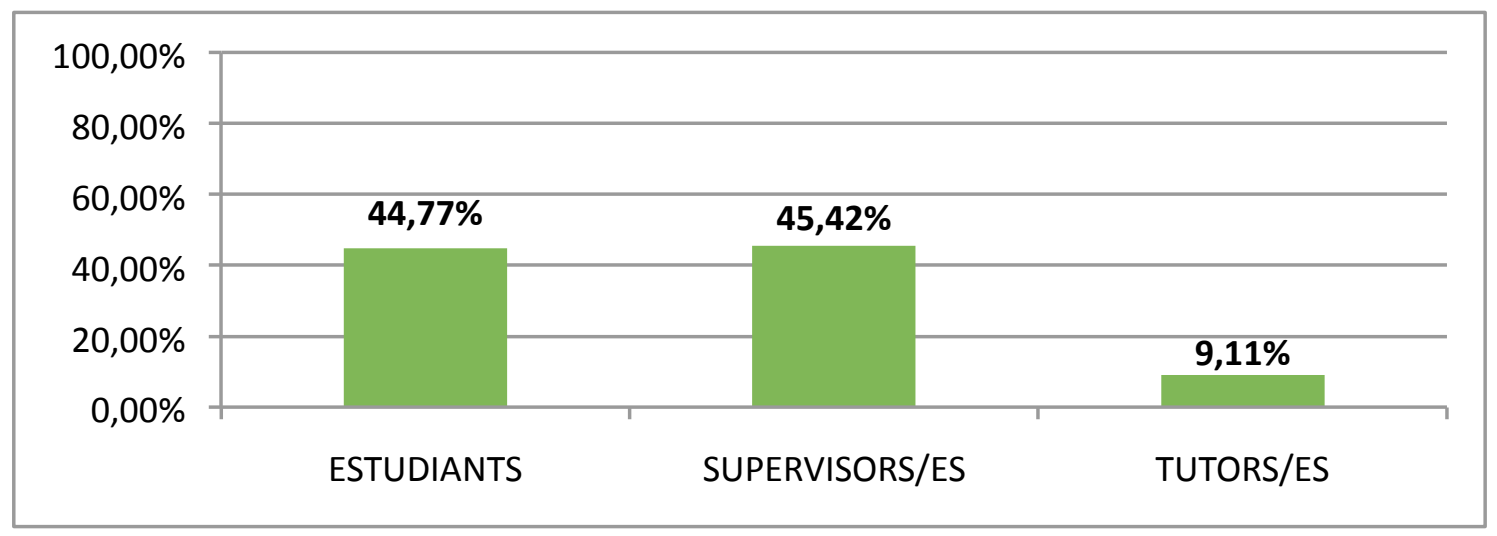

Figura 2

Increment taxa de resposta curs 2016-2017 respecte al curs 2015-2016

Finalment la taula 4 mostra els resultats del contrast estadístic khi quadrat que s'ha dut a terme. Com es pot comprovar, en els tres casos hi ha un canvi estadísticament significatiu en l'increment de la mostra recollida entre el curs passat i l'actual.

Taula 4

Estadístic khi quadrat

\begin{tabular}{lrrrr}
\hline & Curs 2015-2016 & Curs 2016-2017 & g.l. & \multicolumn{1}{c}{ X $^{2}$} \\
\hline Estudiantat & $23,65 \%$ & $68,42 \%$ & 1 & $1113,12^{* * *}$ \\
\hline Tutors/es & $39,91 \%$ & $49,02 \%$ & 1 & $12,011^{* *}$ \\
\hline Supervisors/es & $15,75 \%$ & $61,17 \%$ & 1 & $1107,780^{\star * *}$ \\
\hline
\end{tabular}

\section{Discussió i conclusions}

S'ha donat un pas important cap a l'ús de mètodes combinats (mixed-mode surveys) de recollida de dades d'enquesta per a millorar la taxa de resposta i la qualitat de les dades combinant qüestionari en línia i reforç telefònic.

En primer lloc, la nova metodologia és efectiva a l'hora d'augmentar la taxa de resposta, aconseguint d'aquesta forma l'objectiu plantejat. En els tres col-lectius enquestats (estudiantat, supervisors/es i tutors/es) hi ha un augment de resposta interanual estadísticament significatiu, de magnitud considerable en el cas de l'estudiantat i els supervisors. Com a conseqüència de l'increment en la taxa de resposta, els resultats obtinguts presenten una major representativitat.

En segon Iloc, i en referència al col-lectiu de tutors/es, tot i no haver estat aplicada la nova metodologia, s'observa que la taxa de resposta s'ha incrementat lleugerament, però de manera estadísticament significativa. Podria dir-se que la no aplicació de la nova metodologia fa que l'augment en la resposta siga menor en comparació als col-lectius estudiantat i supervisor/es. Pel que fa a l'increment en la taxa de resposta, aquesta podria ser deguda a la consciència creixent de la importància de contestar aquesta enquesta, així com a un major coneixement del 
procés d'avaluació institucional com a conseqüència d'una creixent acció informativa any rere any.

L'enviament de recordatoris personalitzats, és a dir, únicament enviats si la persona no ha contestat l'enquesta, ha suposat una disminució en les queixes que prèviament provocava l'enviament indiscriminat de recordatoris.

A més dels resultats obtinguts referents a la taxa de resposta, també s'han observat increments en els indicadors de satisfacció per als dos collectius estudiats. S'observa una major satisfacció global amb les pràctiques, una major intenció de tornar a acollir estudiantat i una major recomanació de l'entitat per a realitzar les pràctiques externes. Com a futures investigacions, es planteja estudiar aquests increments per a poder oferir-ne una explicació.

Finalment, pel que fa a les limitacions de l'estudi, cal que el pla formatiu de les pràctiques de l'estudiantat estiga correctament complimentat, especialment els camps de data i correu electrònic. Aquestes dues dades són requerides pels programes informàtics $\mathrm{i}$, per tant, són dades claus per a garantir la bona execució del procés d'avaluació.

\section{Referències bibliogràfiques}

Beas, María Isabel i Raül Burriel. 2007. «Diseño y validación mediante análisis factorial de los cuestionarios de evaluación de la calidad de las estancias en prácticas de la Universitat Jaume I: Alumnos, tutores y supervisores». En Actas IX Simposium de Poio. Buenas prácticas en el practicum (153-166). Poio: Asociación Iberoamericana de Didáctica Universitaria (AIDU).

—. 2017. "Seguimiento de la inserción laboral de egresados universitarios: revisión y actualización del modelo UJI». En Actas de la V Jornada Nacional sobre Estudios Universitarios: estructura de títulos v3.2., ed. Joaquim Beltrán i María Ripollés (485-494). Castelló de la Plana: Publicacions de la Universitat Jaume I.

Burriel, Raül i María Isabel Beas. 2008. «El procedimiento de análisis de la inserción laboral de los graduados: una propuesta de modelo longitudinal». En Actas de la Jornada Nacional sobre Estudios Universitarios: de los proyectos de convergencia a la realidad de los nuevos títulos (2-8). Castelló de la Plana: Publicacions de la Universitat Jaume I.

Díaz de Rada, Vidal. 2012. «Ventajas e inconvenientes de la encuesta por Internet». Papers: revista de sociologia 97 (1): 193-223.

Dillman, Don A., Glenn Phelps, Robert Tortora, Karen Swift, Julie Kohrell, Jordi Berck i Benjamin L. Messer. 2009. "Response rate and measurement differences in mixed-mode surveys using mail, telephone, interactive voice response (IVR) and the Internet». Social Science Research 38(1): 1-18.

García, Laura i María Isabel Beas. 2013. «Las prácticas externes: un medio para desarrollar competencias. Los proyectos formativos como núcleo de la gestión y evaluación». En Actas de la IV Jornada Nacional sobre Estudios Universitarios: El futuro de los títulos universitarios (516-527). Castellón de la Plana: Publicacions de la Universitat Jaume I.

González, Julia i Robert Wagenaar (ed.). 2003. Tuning Educational Structures in Europe: Final Report. Phase One. Recuperat de: http://tuningacademy.org/wpcontent/uploads/2014/02/TuningEUI_Final-Report_EN.pdf [Consultat el 16 de gener de 2019].

Páramo, Raúl. 2007. «Pros y Contras de la investigación on-line». MK Marketing+Ventas 225: 8-15. 